\title{
Concept \& Implementation of Three-Layered Vessel Traffic Management System
}

\author{
Min Jung* $\cdot$ Chae-Uk Song ${ }^{\dagger}$ \\ * Statutory Service Team, Korean Register of Shipping, Daejeon 305-343, Republic. of Korea \\ + Division of Navigation Systems Engineering, Korea Maritime University, Busan 606-791, Republic. of Korea
}

\begin{abstract}
Recently IMO and IALA have developed the strategy of $e^{-N a v i g a t i o n}$ and the concepts of VTM to enhance the safety, efficiency and security of vessel traffic and protection of the marine environment. And current technical and functional trends require vessel traffic management systems to be improved so as to control vessel traffic not only in waters of harbour area, but also within EEZ waters. Under the consideration of these circumstances, a three-layered vessel traffic management system was proposed in this paper. The proposed system consists of three sub-systems, called Local VTS, Regional VTS and National VTS, and those sub-systems are designed respectively to be suitable for managing vessel traffic within their own jurisdiction waters.
\end{abstract}

Key words : $3 L-V T M, e^{-N a v i g a t i o n, ~ L o c a l ~ V T S, ~ R e g i o n a l ~ V T S, ~ N a t i o n a l ~ V T S ~}$

\section{Introduction}

With the large amount of marine traffic and the advent of huge vessels with dangerous cargoes, many countries have operated VTS(Vessel Traffic Service) to prevent marine casualties and oil spills which may cause the loss of human lives, properties and marine pollution in their coastal waters.

Recently IMO(International Maritime Organization) and IALA(International Association of Marine Aids to Navigation and Lighthouse Authorities) have developed the strategy of e-Navigation and the concepts of VTM(Vessel Traffic Management) and VTMIS(Vessel Traffic Management and Information Service) to enhance the safety, efficiency and security of marine traffic and protection of the marine environment(IALA, 2008 ; IMO, 2007). And current technical and functional trends require marine traffic management systems to be improved so as to control marine traffic not only in waters of harbour area, but also within EEZ waters(Jan-Hendric, 2006).

Since nineteen ninety-two, thirteen port VTS systems have been established in all of trading ports in Korea, and two coastal VTS systems have been installed to provide comprehensive information to all ships sailing around Jindo and Wando coastal waters. It has been proved that those VTS systems helped to increase the safety and efficiency of vessel traffic and to keep the marine environment from possible marine disasters.

However, in spite of the fact that those systems have obviously played an important role in taking measures necessary to navigational safety, their short coverages still remains unsolved and makes VTS systems difficult to get or provide information from/to the vessels navigating far from the coast(Mike, 2006).

In this paper, we propose a three-layered vessel traffic management (3L-VTM) system which consists of three sub-systems designed respectively to be suitable for managing vessel traffic within their own jurisdiction waters.

\section{International trends in vessel traffic management}

\section{1 e-Navigation}

IMO has developed the strategy of $\mathrm{e}^{-}$Navigation since 2007, and adopted the definition of $\mathrm{e}^{-}$navigation as the harmonized collection, integration, exchange, presentation and analysis of maritime information onboard and ashore by electronic means to enhance berth to berth navigation and related services for safety and security at sea and protection of the marine environment.

With the development of existing and future technological infrastructure onboard and ashore, $\mathrm{e}^{-}$Navigation would be an opportunity to optimize these developments, and ensures that the focus of future developments is on a holistic approach to safe navigation from berth to berth. The outcomes of $\mathrm{e}^{-}$Navigation would be focused in turn on the onboard, shore and communications elements of $\mathrm{e}^{-}$Navigation.

Those outcomes are expected to influence and change

\footnotetext{
* minj@krs.co.kr (042)869-9354

† Corresponding Author : songcu@hhu.ac.kr, 051)410-4272
} 
maritime traffic management system by efficiently appling modern digital technology and communication architecture. And also they could improve the exchange of information from ship to shore, shore to ship and between shore-based stakeholders, both on an authority and business level(Jung, 2005).

\subsection{VTM}

VTM is defined as the set of efforts(measures, provisions, services and related functions) which intend to minimize risks for the safety of vessel traffic and the marine environment, whilst maximizing the efficiency of waterborne and connecting modes of transport. And it is also a collection of global activities supported by information services that address the safe, secure, and efficient interaction of vessels.

The development of VTM makes the existing VTS evolve into the new version of vessel traffic management which could provide information positively to the vessels and be closely connected with several relevant activities or systems relating to the safety of navigation. As shown in Fig. 1, functional scope of VTM involves the operation of search and rescue (SAR), the maintenance of aids to navigation (AtoN) and the exchange of information with the third parties of maritime affairs.

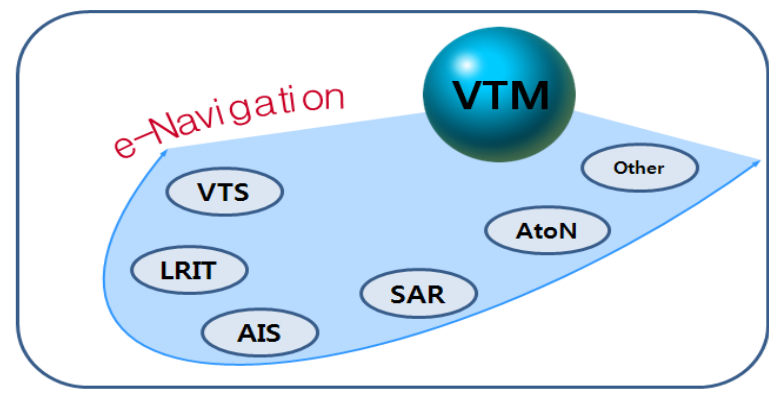

Fig. 1 Functional scope of VTM

\subsection{Other international trends relating to VTS}

With the advent of modern information and communication technology, both the operational concept and the area of jurisdiction of VTS have been changing. The extent of VTS area tends to be enlarged from coastal waters to the high seas, and additional functionalities, such as mutual assistance and closer cooperation with relevant systems, would be required to be added to VTS(Jeong, 2006).

International efforts to construct the long-range identification and tracking (LRIT) system and the automatic identification system using low earth orbit satellites helped to extend the range of vessel tracking capabilities. And those efforts also contributed to enhancement of the safety of the vessel operations at sea and the efficiency of the SAR operations.

\section{Present state of related systems in Korea}

The objective of Port VTS is to provide various information in order to prevent accidental vessel collisions and to promote safe port operations. Since the first installation of Port VTS was finished in 1992 in waters both within the harbour limit of Pohang port and of 6-mile radius from Homigot, thirteen Port VTSs have been established in all trading ports along the coastal waters of the Korean Peninsula.

Coastal VTS aims to reduce the risks of maritime casualties in coastal waters of high traffic density, and provides all ships sailing in its jurisdiction waters with comprehensive information. Two Coastal VTSs have been installed since 2004 around waters of Jindo and Wando to monitor the movement of vessels for the purpose of prevention of marine casualties and protection of environment. Fig. 2 shows current status of Port and Coastal VTSs installed in trading ports and along coastal waters of Korea.

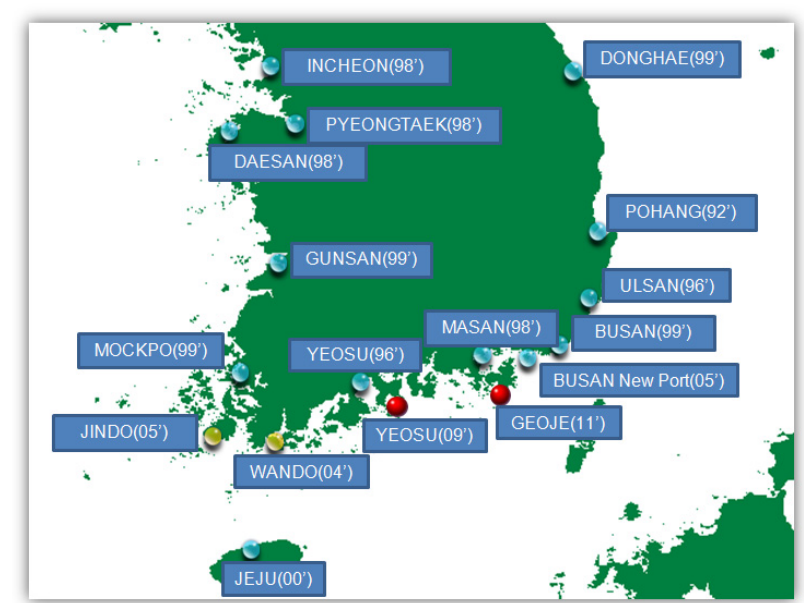

Fig. 2 Current status of VTS in Korea

However, because those VTSs were designed in the initial stage to monitor vessels navigating only within or near waters of harbour limit, it was unable to get information from vessels navigating off the coast. And also they were installed separately without the consideration of integration, it was difficult to increase the efficiency in data transmission by exchanging necessary information with each other.

As described the above, recently VTS area of competence 
would be wider up to coastal waters and high sea by using sensors such as Radar, AIS and LRIT. And all information from the relevant authorities such as AtoN, SAR would be integrated for improving the efficiency of maritime traffic, and those information would be exchanged with other or adjacent VTS centers.

\section{Implementation of 3L-VTM system}

\subsection{Definition and service of the system}

3L-VTM is the system for the safety of life at sea and protection of marine environment by exchanging vessel traffic information with relevant systems and enlarging VTS area up to coastal waters and high sea.

And as shown in Fig. 3, 3L-VTM carries out positive surveillance service with RADAR, AIS and CCTV in territorial waters, and from out of territorial waters to EEZ, it performs passive monitoring service which is depending on ship's reporting.

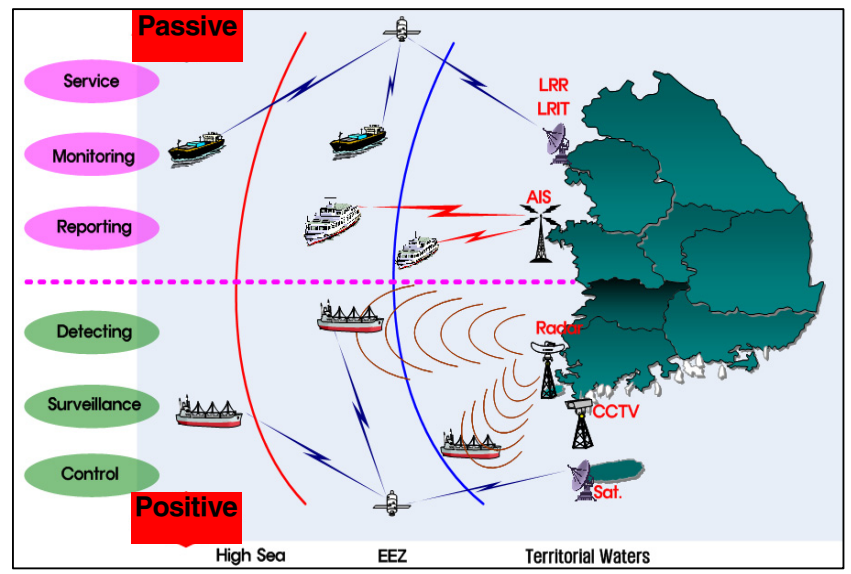

Fig. 3 Service type and area of 3L-VTM

\subsection{Essential components for enlarging competent area}

IMO adopted new regulations in May 2006 for the LRIT and included them in SOLAS chapter $\mathrm{V}$ on Safety of Navigation. SOLAS contracting governments would be entitled to receive information about ships navigating within a distance not exceeding 1,000 nautical miles off their coast every 6 hours by satellite system. The LRIT information will be required to include the ship's identity, location, date and time of the position.

The AIS provides automatically to appropriate equipped shore stations and other ships information including ship's identity, type, position, course, speed, navigational status and other safety-related information. And it improves the safety of navigation by assisting in the efficient navigation of ships, protection of the environment and operation of VTS(Jeong, 2003).

And Radar is an electromagnetic system for the detection and location of ships, and has performed its function as the main constitution of VTS system. With the development of Radar techniques, it has been possible to detect vessels at much longer range and help VTS to overcome its own limitations on the range of surveillance.

\subsection{Architecture of the system}

3L-VTM system consists of three sub-systems, Local VTS, Regional VTS and National VTS. As described in Table 1 and Fig. 4, those sub-systems are designed to manage vessel traffic within their own jurisdiction waters with suitable communication components respectively.

Table 1 Specification of three sub-systems

\begin{tabular}{|c|l|l|l|}
\hline & Local VTS & Regional VTS & National VTS \\
\hline Area & $\begin{array}{l}\text { Within } \\
\text { Harbour } \\
\text { waters }\end{array}$ & $\begin{array}{l}\text { Coastal water } \\
- \text { EEZ }\end{array}$ & High sea \\
\hline $\begin{array}{c}\text { Comm. } \\
\text { Tech. }\end{array}$ & $\begin{array}{l}\text { VHF, } \\
\text { Radar/AIS }\end{array}$ & $\begin{array}{l}\text { VHF, } \\
\text { Radar/AIS, } \\
\text { LRIT }\end{array}$ & $\begin{array}{l}\text { LRIT, } \\
\text { Other Sat. } \\
\text { System }\end{array}$ \\
\hline $\begin{array}{c}\text { fojecti } \\
\text { ve } \\
\text { positive VTS } \\
\text { for safety and } \\
\text { efficient } \\
\text { operation of } \\
\text { harbour }\end{array}$ & $\begin{array}{l}\text { safety of } \\
\text { marine traffic } \\
\text { and protection } \\
\text { of marine } \\
\text { environment } \\
\text { in coastal } \\
\text { water }\end{array}$ & $\begin{array}{l}\text { decision - } \\
\text { making center } \\
\text { in emergency } \\
\text { situation and } \\
\text { safety of } \\
\text { navigation in } \\
\text { high sea }\end{array}$ \\
\hline
\end{tabular}

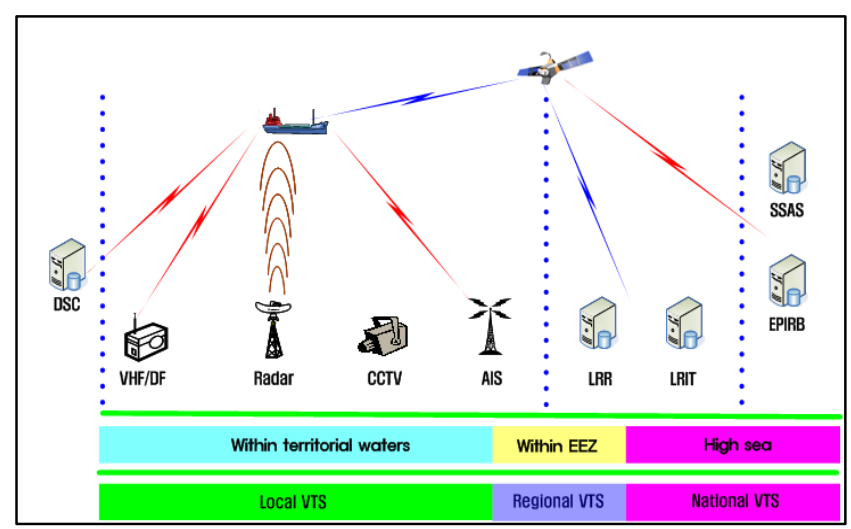

Fig. 4 Communication components of 3L-VTM system

\section{(1) Local VTS}

Local VTS implements a role of existing port VTS to provide information with vessels for the safety and efficient operations of harbour. It performs the surveillance of its area of competence by using RADAR, AIS, VHF and VHF/DF, and also utilizes all integrated information from Regional VTS to increase its performance. 
(2) Regional VTS

Regional VTS provides maritime safety information with vessels in coastal waters and monitors vessels traffic as far as EEZ waters to assist the safe and expeditious passage of shipping through coastal waters. It would be installed in waters where there are high density of maritime traffic, environmental sensitivity and difficult navigation conditions.

As shown in Fig. 5, Regional VTS is interfaced with Local VTS and National VTS, exchanges necessary information with them. In case of emergency when a connected Local VTS system could not function well, it performs a back-up system by controlling directly communication components such as Radar, AIS and VHF originally belonging to the Local VTS.

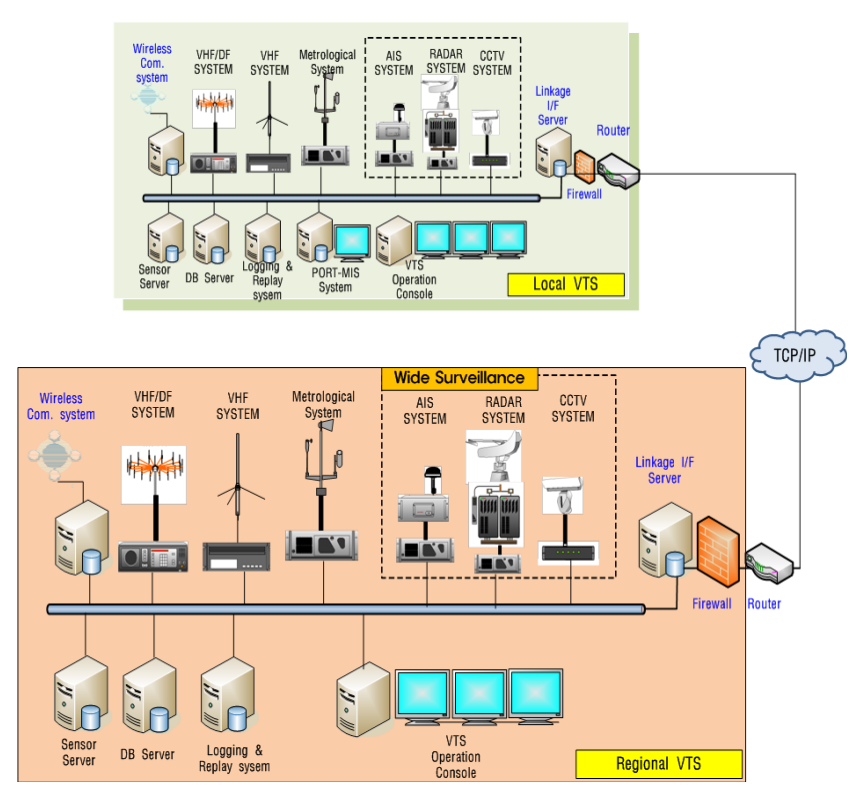

Fig. 5 Connecting link of regional VTS with local VTS

In consideration of the volume and density of traffic, four Regional VTSs are suggested in all waters along the Korean coastline. Fig. 6 shows lines of demarcation of four Regional VTSs.

\section{(3) National VTS}

National VTS is aimed to monitor all Korean flag ships navigating in waters beyond domestic jurisdiction. As shown in Fig. 7, in order to exchange and integrate marine information, it is connected not only with Regional \& Local VTS. It is also connected with other relevant systems to help Korean Coast Guard to operate SAR operation and to provide the related authorities with traffic information.

In addition, National VTS exchanges ship's traffic data with foreign authorities to enhance navigational safety and reduce the risk of marine casualties and damages to the marine environment.

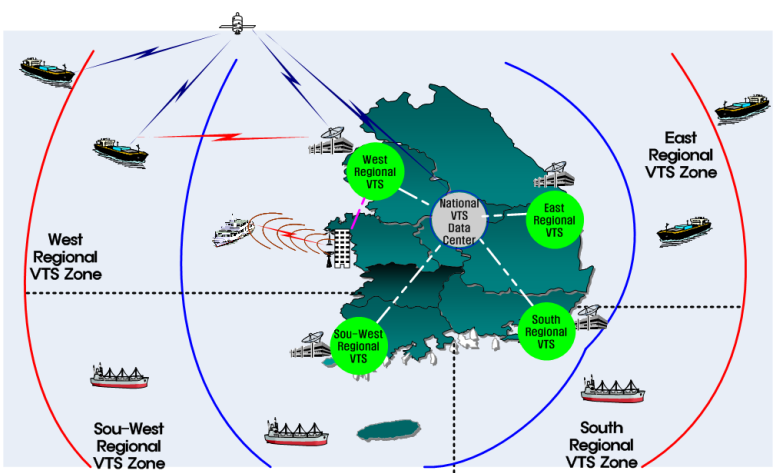

Fig. 6 Line of demarcation of regional VTS

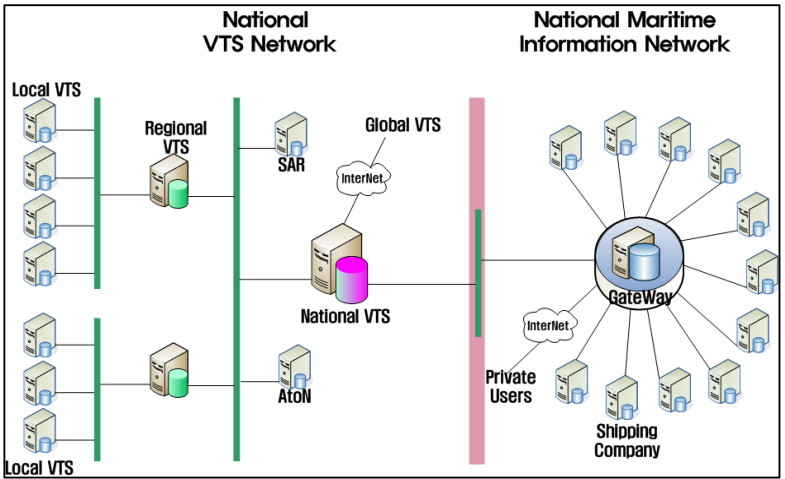

Fig. 7 Connecting link of national VTS

\subsection{Data standardization of the system}

To perform its tasks, 3L-VTM system is designed to communicate with lots of maritime traffic systems by XML file transfer which is a general-purpose specification for creating custom markup languages. $\mathrm{XML}$ is proposed for new standard to make up for the weak points in HTML, and it transfers structured data to local computing system by several application program.

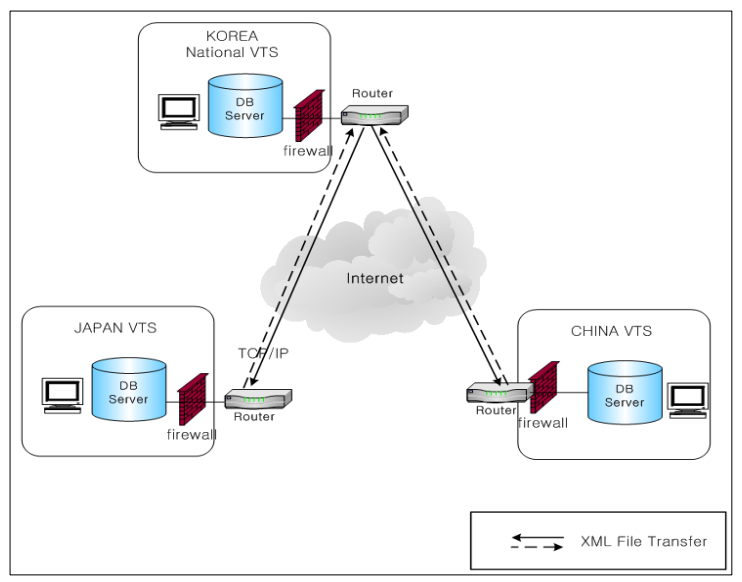

Fig. 8 Date exchanges with foreign VTS systems 
It was recommended in IALA's VTS committee that XML format would be appropriate for the way of exchanging data between VTS centers. XML format was selected by UN/EDIFACT as a standard for exchanging information relating to logistics. As shown in Fig. 8, 3L-VTM is based on TCP/IP protocol of Internet/Web service to exchange data with other systems, and receives Korean ship's tracked data from other nation's VTS system.

\section{Conclusion}

In this paper, as a new version of vessel traffic management, 3L-VTM was proposed not only to get or send information from/to the vessels navigating far from the coast, but also to provide existing VTS systems with international technical trends in maritime traffic management such as $\mathrm{e}^{-}$Navigation, VTM and standard for data exchange.

The proposed system could perform positive surveillance service in territorial waters and passive monitoring service from out of territorial waters to EEZ by using LRIT, satellite based AIS and long-range Radar. And it consists of three sub-systems and they manage vessel traffic within their own jurisdiction waters with suitable communication components.

It also designed to exchange necessary data with lots of maritime traffic systems through XML file transfer which was recommended as a way of exchanging data between VTS centers. It could be possible even to exchange vessel traffic data with VTS systems of neighboring countries such as China and Japan.

It would be expected to help enhance the safety and efficiency of vessel traffic and to play an important role for navigational safety by performing comprehensive surveillance.

\section{References}

[1] Hadley, M. (2006), "How to Make the Most of Your Coastal VTS", 16th IALA Conference, pp. 55-62.

[2] IALA AISM (2008), "VTS Manual”, No. 1, pp. 41-58.

[3] IMO (2007), "Development of an e-Navigation Strategy", NAV 53/13 pp. 3-15.

[4] Jeong, J.S., Nam, T.K., Kim, C.S., Park, S.H., Yim, J.B., and Ahn, Y.S. (2006) "International Trends on Vessel Identification and Tracking and E- Navigation Strategy", Spring Conference of Korean Navigation and Port Research, Vol. 30, No. 1, pp. 105-111.

[5] Jeong, J.S. and Yang, W.J. (2003), “A Study on the Enhancement of Utilization of Automatic Identification
System", Journal of The Korean Society of Marine Environment \& Safety, Vol. 9, No. 2, pp. 15-21.

[6] Jung,M., Song, J.U., Yea, B.D., Park, J.S., Lee, Y.S., and Park, Y.S. (2005), “A Study on Standardization of Interfacing Technology, Between, Components of Coastal Intelligent Transport System”, Fall Conference of Korean Navigation and Port Research, Vol. 19, No. 2, pp. 31-32.

[7] MarNIS Project (2005), http://www.marnis.org.

[8] Ministry of Land Transport and Maritime Affairs, "GICOMS" (2009), www.gicoms.go.kr.

[9] Oltmann, J. H. and Bober, S. (2006), "The implementation of a coastal-wide AIS service", 16th IALA Conference, pp. 27-35.

Received 16 June 2008

Revised 9 February 2010

Accepted 10 February 2010 